Scholedge International Journal of

Management \& Development

ISSN 2394-3378, Vol.05, Issue 10 (2018)

$\operatorname{Pg} 114-120$.

DOI: 10.19085/journal.sijmd051001
Published by: Scholedge Publishing

www.theSCHOLEDGE.org

Email: editorial@thescholedge.org

(C) Publisher

\title{
Does Technology and ICT Capabilities Affect Performance of a Firm: An Exploration of Small \& Medium Enterprises?
}

\author{
Dr. Abid Sultan \\ Faculty, Department of Management Studies, University of Kashmir, J\&K India.
}

\begin{abstract}
The study explores the relationship between technology and the competitive performance of SME's involved in the agro-food processing business in developing countries like India. The study focuses on describing firm level competitiveness through the technology of selected agro-food processing firms of agriculture and horticulture rich state of India i.e. Jammu and Kashmir. The study is exploratory in nature. The study is largely based upon the primary data collected through a well-structured questionnaire. The results indicate a positive relationship between technology competence \& total competitive performance and supports the importance of the technology in improving firm level competitiveness. The results of the present study will be helpful to the SME's in shaping their present and future competitive position as well as improving the competitiveness. The results can also be beneficial to the policymakers in formulating competitiveness related policies and strategic development of the SME's.
\end{abstract}

Keywords: Technology, Competitive Performance, Competitiveness, Firm-Level Competitiveness.

\section{INTRODUCTION}

Developing economies, like India, are becoming the manufacturing hubs of the world and therefore require specific strategic interventions for improving efficiency and effectiveness of the production processes in the firms, especially in small \& medium sized firms (Teece et al., 1997). With increasing global competition, changing business models and consumers preferences, it is inevitable for firms to develop specific competencies that can improve their competitive performance in industry and at the marketplace. Firms with distinctive competencies compete in an effective manner in the competitive markets (Chaudhuri \& Ray, 1997; Teece et al., 1997). Distinctive competencies arise in a firm due to the firm's internal resources and capabilities. Competencies, like technology, describe the success and failure of a firm in an industry. Technology competence defines the efficiency of a production process in a firm, besides also helps improves monitoring of competition dynamics, understanding customer tastes \& preferences, ensuring customer relationship management, database management, information management \& processing as well building innovative capabilities. Technology is a central pillar of the inputtransformation-output production model of a firm and it greatly influences the productivity of a firm and quality of the final product. With the increasing technology advancements in the manufacturing sector accompanied with reducing technology costs \& easy availability, especially ICT based technologies, investing money for building \& expanding technology competence of a firm is a very much required from a firm operating in a high competitive environment.

Manufacturing firms of developing countries such as India are largely small and medium-sized enterprise and exploration of technology competence of such firms are still in an infancy stage. Further, the influence of technology competence (including ICT capabilities) on the competitive performance of the small \& medium sized firms in India is still an unexplored area in certain industries such as agro-food processing industry, especially at the regional levels. Thus, creating a scope for defining the technology competence and competitive performance of 
SME's at the regional, which face multiple challenges in their day to day operations. Within this background, the present study describes the competitive performance \& technology competence of SME's and also explains the relationship \& interaction between them. The study is significant in terms of understanding the competitive performance\& technology competence of the firms located in a hill \& conflict driven economy as well as in understanding their associations with each other. The study proposes technology and ICT as an inseparable element for improving the competitive performance of the small \&medium sized enterprises. The proposition has been tested on small \&medium sized enterprises involved in the agro-food processing industry, which are highly technology driven in their operations. The paper ahead discusses the review of literature, research methodology followed by the findings and discussions on the technology competence \& competitive performance.

\section{LITERATURE REVIEW:}

Competitive performance is a significant thought for ensuring competitiveness as well as the growth of firms, industries, and nations (Joshi et al., 2011). The industrial-organizational economies, research traditions focused upon the firm's superior financial performance and relative performance at the marketplace with respect to their competitors, supplier, and influence upon the customers (Porter, 1980). Chamberlin's heterogeneous demand theory focused upon the substantial heterogeneous of intra industry demand where the product is defined broadly (Alderson, 1957). Differential advantage theory of competition at a firm level focuses upon the firm's influence with respect to the economic performance (Alderson, 1957). The prominence of competitive performance lies in explaining the competitiveness at a firm level (Chenhall, 2005; De Toni et al., 1997). Firm-level competitiveness is an essential \& basic level of competitiveness which provides for enhancing industry \& international level competitiveness as it leads to the competitive firms which form the base for a successful industry \& nation. Competitive firms are revenue and employment generation entities. Thus, they lead to the growth of a nation and increase the standard of its people (Buckley et al., 1988).

The importance of firm-level competitiveness lies in the competitive performance of a firm (Singh et al., 2007). Performance measurement of a firm is an outcome of both financial and non-financial parameters, which gives a holistic \& broad picture of the competitive performance of a firm (Sanchez et al., 2012). Competitive performance of a firm can be explained through the summation of measures of manufacturing, marketing and financial performance (Cleveland et al., 1989). Manufacturing measures consist of cost, quality, dependability/delivery and flexibility (Kim \& Arnold, 1992; Kumar et al., 1999; Hung et al., 2015; Shahnawaz, 2015; Ward et al., 1998). Marketing performance can be explained by the sales performance (Lau, 2002; Sharma \& Fisher, 1997) and financial performance through profit after tax (Buckley et al., 1988; Fischer \& Schornberg, 2007). The inclusion of financial and non-financial explains the performance of a firm in an inclusive manner.

The resource-based view (RBV) of the firm provides insight towards the competitiveness of the firm's ability to combine the heterogeneous and imperfect mobile resources that may be tangible or intangible (Barney, 1991). The competitiveness affinity with the resource advantage can be traced with the industry organization economies where the firm's objective is the superior performance. The resource-based theory views firms as efficiency seekers. It defines that the size and scope of the firm as a result of efficiency differences. However, it also goes further to describe the competitiveness based upon the effectiveness gained out of new products and technologies, though both of these have been attributed as the exogenous drivers of competition. It considers internal competitive resources of a firm, both tangible and intangibles resources, like technology, marketing, human resource, innovation capabilities etc. as its sources (Porter, 1990; Ambastha\& Momaya, 2004; Prahalad \& Hamel, 1990, Chaudhuri \& Ray, 1997). However, there are certain complexities involved in understanding the role of internal competencies in the firm level competitiveness. This is mainly due to the qualitative nature of the competencies along with the availability of data on these competencies.

Firm in the industry needs to build competencies that lead to enhanced competitive performance and thus firm level competitiveness (Pertusa-Ortega et al., 2010; Barney, 1991; Porter, 1990). Literature suggests multiple internal resources that have the potential of improving competitive performance of a firm such as firm's structures, capabilities to innovate, the ability to market, technology, productivity, human resources management, operations management, supply chain management etc. (Prahalad \& Hamel, 1990; Ambastha\& Momaya, 2004 and Chaudhuri \& Ray, 1997).Technology is an important factor for enhancing the competitiveness of the firms because technology affects price structures by bringing flexibility in the operations \& processes of the firm as well as leads to better quality products. Technological competence provides high return and creates a position barrier for the firm. New technology adoption or upgradation favors lowering of the production cost, enhancement of the quality and affects 
the firm level competitiveness (Kennedy et al., 1998). Technology helps small-sized firms to innovate at a faster pace, respond to the customer needs quickly, fast production, customization and variety etc. (Meredith, 1987). Firms with a strategic orientation for technological competence will have improved competitive performance and capabilities (Day, 1994; Tracey et al., 1999). The technology essentially determines the prospectus of an enterprise in an industry with high competition levels. Besides, manufacturing technologies the essence of the information and communications technology (ICT) has increased manifolds in an organization in the recent past. This may be attributed to the digital revolution taking place across the globe and industries. ICT is a computer-aided technology for managing, storing, processing and communicating the data within an organization (Molloy \&Schwenk, 1995). ICT constitute embedded business processes and investments in the hardware, software, data and people (Reddy, 2006). Various studies advocate the implementation of the ICT in a firm because of its numerous benefits upon which an organization can leverage. ICT provides for effective management of information in a firm and also improves access to the information such as market information, customer information, supplier information, inventory information etc. It has led to the efficiency and effectiveness of a firm through the electronic data interchange (Boudreau et al., 1998; Reddy, 2006). It has reduced the reaction time of a firm towards business problems and trails and thus has made them quick and responsive towards business environment (Ansoff, 1975). ICT has improved the decision making proficiency of a firm through rapid and apt information transfer (Molloy \&Schwenk, 1995). ICT promotes effective \& efficiency in a firm's day to day operation which intrinsically leads to improved competitive performance and thus firm level competitiveness.

The comprehensive review of the literature on competitiveness \& competencies supports firm level competitiveness as an outcome of the internal resources of a firm. From a strategic management perspective, firmlevel competitiveness is significant for strategic positioning of a firm in a national and international market. The strategic positioning of a firm makes it indispensable to identify strategic areas of interventions which contribute to the high performance, the firm's strategic objectives and industry standards. This becomes more important in the context of the developing nations, especially at their regional levels and in their small and medium enterprises. There is a gap in the literature regarding understanding the competitive performance of small \& medium enterprises and influence of technology competence on their competitive performance in developing economies like India, especially at the regional levels, which needs to be bridged in.

\section{RESEARCH METHODOLOGY:}

The key objective of the present study is to comprehend the relationship between the technology competence and competitive performance of a firm and the influence thereof. The study on the basis of literature review describes the competitive performance and technology competence of a firm. The data pertaining to competitive performance and technology competence has been collected through a well-structured questionnaire with Cronbach's coefficient alpha of 0.83 . The questionnaire has been administered on 82 manufacturing firms involved in agro-food processing, out of which data from 61 firms have been found complete for the data analysis.

Construction of Performance Index (PI): Performance index in the present study has been defined by taking both financial and non-financial variable, thus explaining PI in a holistic manner (Sanchez et al., 2012). Multiple variables show a holistic and broad picture of the competitive performance of a firm. Six variables i.e. cost, quality, dependability/delivery, flexibility, sales performance and profit after tax (Cleveland et al.,1989; Kim \& Arnold, 1992; Kumar et al., 1999; Hung et al., 2015; Shahnawaz, 2015; Ward et al.,1998; Lau, 2002; Sharma \& Fisher, 1997; Buckley et al., 1988; Fischer \& Schornberg, 2007). The data pertaining to these six variables have been collected on five-point Likert scales by positioning of firms in comparison to other firms by assigning 1 to poor performing firm, 2 to satisfactory, 3 to average, 4 to good and 5 to excellent. The data collected has been normalized by $\log$ transformation. Each of the six variables was transformed into the six individual indices and aggregated to form the competitive performance index. The collective aggregation of these factors described the performance level of the selected firms.

Construction of Technology Competence Index (TCI): Technology has been held as an important and essential element for improving the competitive performance of a firm and thus firm level competitiveness. Technology competence of the studied firms has been described through two aspects i.e. manufacturing technology and ICT aspect. The manufacturing technology aspect of the firms has been measured through the following statements: Use of the automated machines for increasing the production; Use of the automatic machines for warehousing in the firm; Use of automatic machines for packaging of the products; Level of the automatic systems for logistics in the firm; Firm performance due to the investment in the technology on an average period of last five years; Standard of 
the technology being used in the firm in comparison to the national level; Standard of the technology being used in the firm in comparison to the international level and Investment in automation/technology up-gradation with future perspective. The ICT aspect of the studied firms has been measured through the following statements:- Usage of internet-based information systems for forecasting \& distribution management in the firm; Usage/level of Emarketing system of the internet/intranet in the daily administration of the firm; Usage of computers in the firm for file management; Usage of internet-based information system for the procurement of raw material in the firm; Usage of internet-based information system for the procurement of packaging \& other input material in the firm; Usage of database management system for industry/market/customer information; Improvement in employee performance due to the usage of ICT in the firm; Improvement in firm performance due to the investment in ICT on an average period of last five years and Investments in ICT/ICT up-gradation with future perspective. The data pertaining to mentioned statements have been collected on the five points Likert scale. Firms were requested to rate themselves on these statements in comparison to their competitors by assigning value 1 for poor, 2 for satisfactory, 3 for average, 4 for good and 5 for excellent. The data collected were normalized by log transformation. The scores of these statements were aggregated to form the Technology competence index (TCI). The descriptive statistics of the TCI is given table 1.

Measurement Method: To understand the relationship and interaction of technology competence index with the competitive performance index of the studied units, a hypothesis has been formulated i.e.

\section{$H_{0}$ : Technology competence does not impact the competitive performance of a firm \\ $H_{a}$ : Technology competence does impact the competitive performance of a firm}

To understand the impact of technology competence on the competitive performance index of a firm regression analysis has been used with competitive performance index (PI) as a dependent variable and technology competence index (TCI) as an independent variable (Cleveland et al., 1989; Saurabh et al., 2017). The validity of the model has been validated at 5 percent level of significance with an $F$ value of 37.60 .

\begin{tabular}{|l|l|c|c|c|c|}
\hline Table 1: Descriptive Statistics of Technology Competence Index (N = 61) & \multicolumn{1}{|c|}{ Statements } & Min. & Max. & Mean & $\begin{array}{c}\text { Std. } \\
\text { Deviation }\end{array}$ \\
\hline S.No. & \multicolumn{1}{|c|}{} & & & \\
\hline 1 & Use of the automated machines for increasing the production & 1.00 & 4.00 & 1.9836 & .86587 \\
\hline 2 & Use of the automatic machines for warehousing in the firm & 1.00 & 2.00 & 1.9180 & .27659 \\
\hline 3 & Use of automatic machines for packaging of the products & 1.00 & 3.00 & 1.1311 & .46459 \\
\hline 4 & Level of the automatic systems for logistics in the firm & 1.00 & 2.00 & 1.0492 & .21804 \\
\hline 5 & $\begin{array}{l}\text { Firm performance due to the investment in the technology on an } \\
\text { average period of last five years }\end{array}$ & 1.00 & 4.00 & 1.6557 & .75023 \\
\hline 6 & $\begin{array}{l}\text { Standard of the technology being used in the firm in comparison } \\
\text { to the national level }\end{array}$ & 1.00 & 4.00 & 1.6885 & .71974 \\
\hline 7 & $\begin{array}{l}\text { Standard of the technology being used in the firm in comparison } \\
\text { to the international level }\end{array}$ & 1.00 & 3.00 & 1.0984 & .39602 \\
\hline 8 & $\begin{array}{l}\text { Investment in automation/technology up-gradation with future } \\
\text { perspective }\end{array}$ & 1.00 & 3.00 & 1.8852 & .60823 \\
\hline 9 & $\begin{array}{l}\text { Usage of internet based information systems for forecasting \& } \\
\text { distribution management in the firm }\end{array}$ & 1.00 & 4.00 & 1.2787 & .60913 \\
\hline 10 & $\begin{array}{l}\text { Usage/level of E-marketing system of the internet/intranet in the } \\
\text { daily administration of the firm }\end{array}$ & 1.00 & 3.00 & 1.2951 & .49478 \\
\hline 11 & Usage of computers in the firm for file management & 1.00 & 3.00 & 1.6066 & .55614 \\
\hline 12 & $\begin{array}{l}\text { Usage of internet-based information system for the procurement } \\
\text { of raw material in the firm }\end{array}$ & 1.00 & 2.00 & 1.0820 & .27659 \\
\hline 13 & $\begin{array}{l}\text { Usage of internet-based information system for the procurement } \\
\text { of packaging \& other input material in the firm }\end{array}$ & 1.00 & 2.00 & 1.0492 & .21804 \\
\hline
\end{tabular}




\begin{tabular}{|l|l|c|c|c|c|}
\hline 14 & $\begin{array}{l}\text { Usage of database management system for } \\
\text { industry/market/customer information }\end{array}$ & 1.00 & 2.00 & 1.0820 & .27659 \\
\hline 15 & $\begin{array}{l}\text { Improvement in employee performance due to the usage of ICT in } \\
\text { the firm }\end{array}$ & 1.00 & 2.00 & 1.2131 & .41291 \\
\hline 16 & $\begin{array}{l}\text { Improvement in firm performance due to the investment in ICT on } \\
\text { an average period of last five years }\end{array}$ & 1.00 & 3.00 & 1.3279 & .50732 \\
\hline 17 & Investments in ICT/ICT up-gradation with future perspective & 1.00 & 4.00 & 1.8197 & .67102 \\
\hline Source: Authors estimation based on the primary data \\
\hline
\end{tabular}

\section{ANALYSIS\& DISCUSSIONS:}

Competitive positioning of a firm is a result of its investments in the strategic resources, both tangible and intangible. The competitive success of a firm primarily depends on the efficiency \& effectiveness of its inputtransformation-output process, which largely depends on the firm's technology orientation. Technology orientation significantly influences the strategic growth and development of a firm and an industry in an economic system. Technology, both manufacturing, and ICT contributes to the long terms success of the firm in an industry. The competition based upon the technology and economics of performance are deep-rooted characters for a firm level \& industry level competitiveness. However, the resulting endogenous effect of investment in technology capabilities as a direct source of competitiveness is restricted to the large manufacturing firms. While as, small and medium manufacturing firms have remained unexplored, particularly at the regional levels in the developing countries like India. The intervention of technology with the regional resource advantage is restricted to the research focused on regional competitiveness. The present paper empirically describes the competitive performance of the firms based on performance and technology competitiveness in the agro-food processing industry of Jammu \& Kashmir, India.

Competitive performance of a firm described through financial and non-financial parameters represents a comprehensive tool for analyzing firm performance (Saurabh et al., 2017). The study focused on describing the competitive performance of the studied firms using six factors i.e. cost, quality, dependability, flexibility, sales and profit after. The technology competence of the studied firms described manufacturing technology \& ICT aspect of technology orientation \& infrastructure in the surveyed firms (refer to table 1). To understand the association and interaction between the two constructed indices (i.e. PI\& TCI) empirical estimation of the regression analysis is measured. Regression estimation reveals a significant positive relationship between TCI \&PI, with correlation value "R"as0.627at 5 percent level of significance. The value of $\mathrm{R}^{2}$ is found to be 0.394 and thus independent variable i.e. TCI explains nearly forty percent variability in the PI, which is a dependent variable in the present study. Thus, the model measuring impact of TCI on the PI is described as

$$
\mathrm{Y}=\mathrm{c}+\mathrm{aX} \mathrm{X}_{1}------------------------------------------(1)
$$

Where,

$\mathrm{Y}=\mathrm{PI}$.

$\mathrm{X}_{1}=\mathrm{TCI}$

$\mathrm{a}=$ coefficient of technology competence index

$\mathrm{c}=$ constant

Thus, the relation is explained as

$$
\mathrm{PI}=0.94 \text { + } 5.56 \text { (TCI)------------------------ (2) }
$$

The validity of the model is tested through F-test, whose value is observed to be 37.64 statistically significant at 5 percent level of significance. Thus, test statistics conclude the overall goodness of fit of the model. Further, the empirical results reject the null hypothesis and accept alternate hypothesis i.e. technology competence does impact the competitive performance of a firm, which has been taken as a proxy for firm-level competitiveness for the surveyed agro-food processing firms in the state of $\mathrm{J} \& \mathrm{~K}$ in India. Test statistics reveals that with one unit investment in building technology competence, competitive performance of the surveyed firms will increase by 5.56units. Therefore, technology competence impacts the competitive performance in a significant and positive manner and contributes towards firm level competitiveness in the long run.

The results reveal the essence of technology in building the firm level competitiveness of the studied SME's. The results hold technology as an essential factor contributing towards enhancing the competitive 
performance of the studied firms. In small \& medium enterprises, technology competence significantly improves efficiency, effectiveness, and flexibility in the operations and manufacturing processes as well as helps them in producing better quality products. Technology competence on one side increases return to the firms as well as improve their innovative capabilities, respond to market \& customer needs at a faster speed, customization \& variety, lowering of the production cost, enhancement of quality and affects the firm competitiveness etc. (Meredith, 1987; Kennedy et al., 1998). Technology competence in terms of Information \&communications technology (ICT) aspect can be helpful to the firms in improving access to the market information, responding to the changing customer preferences \& taste, increase response to the environment threats \& challenges, facilitates quick and information-based decision making (Boudreau et al., 1998, Reddy, 2006; Ansoff, 1975; O Reilly, 1978; Molloy \&Schwenk, 1995).

During the survey, it has been observed that the SME's of agro-food processing industry in Jammu \& Kashmir have started realizing the essence of the technology competence for improving firm level competitiveness and thus have started investing in production technology, technology upgradation and most importantly in information, communication and technology. However, during the survey, it was also observed that technology management is being carried out without any proper planning and need evaluation. The present study observes that the technology competence holds potential in defining the competitive performance of the SME's and can also lead to growth. Technology competence offers advantageous scope to the SME's through automation of the key production processes, up-gradation, creating linkages with employees, suppliers \& buyers and network of distributors. However, there may be certain challenges involved in the building technology competence among SME's. Most of the SME's are family and traditional oriented business with a low orientation towards technology advancements. Besides, financial implication associated with technology upgradation also act as the main hurdle to the technology competence. Also, some SME's are in transition from the first generation to the second generation, which sometimes creates a conflict of opinion. These factors in SME's need to be resolved amicably and efforts should be directed towards leveraging upon investment in technology.

\section{CONCLUSION:}

The present study focused on analyzing technology competence and firm level competitiveness in SME's. The study reveals a positive relationship between firm-level competitiveness and technology competence of SME's. The study has been carried on Agro-food processing manufacturing firms in the state of J\&K. The results reveal that SME's can improve their competitive performance through technology competence. Technology competence acts as a tactical input towards the strategic intervention for the growth and development of the SME's in developing and regional economies. Implementation of the ICT along with the modern production technology goes in a long way towards improving the competitive performance. The present study has a certain limitation in terms of availability of absolute data, as small and medium firms do not have a proper database over the various variables as well as the orientation of the SME's towards research. However, the present study made an effort towards highlighting the role of technology in firm-level competitiveness among SME's. The results can be beneficial to entrepreneurs in understanding the link between technology and competitiveness. It can also be advantageous to the policymakers in framing policies for the SME's.

\section{REFERENCES:}

[1]. Alderson, W. (1957). Marketing Behaviour and Executive Action. Homewood, IL: Richard D Irwin.

[2]. Ambastha, A., \& Momaya, K. K. (2004). Competitiveness of Firms: Review of theory, frameworks \& models. Singapore Management Review, 26(1), 45-61.

[3]. Ansoff, H. (1975). Managing Strategic Surprise by Response to Weak Signals. California Management Review, 18(2), 21-33.

[4]. Barney, J. (1991). Firm Resources and Sustained Competitive Advantage. Journal of Management, 17(1), 99-120.

[5]. Boudreau, , M.-C., Loch, , K., Robey, , D., \& Straud,, D. (1998). Going Global: Using Information Technology to Advance the Competitiveness of the Virtual Transnational Organization. Academy of Management Executive, 12(4), 120-128.

[6]. Buckley, P. J., Pass, C. L., \& Prescott, K. (1988). Measures of International Competitiveness :A Critical Survey. Journal of Management, 4(2), 175-200.

[7]. Chamberlim, E. (1933). The Theory of Monopolistic Competition . Cambridge MA: Harvard University Press.

[8]. Chaudhuri, S., \& Ray, S. (1997). The Competitiveness Conundrum : Literature Review and Reflections. Economic and Political Weekly, 32(48), M83-M91.

[9]. Chenhall, R. (2005). Integrative Strategic Performance Measurement Systems, Strategic Alignment of Manufacturing, Learning and Strategic Outcomes: An Exploratory Study. Accounting, Organizations and Society, 30(5), 395-422. 
[10].Cleveland , G., Schroeder, R. G., \& Anderson, J. C. (1989). A Theory of Production Competence. Decision Sciences , 20(4), 655-668.

[11].De Toni, A., Nassimbeni, G., \& Tonchia, S. (1997). An Integrated Production Performance Measurement System. Industrial Management and Data Systems, 97(5), 180-186.

[12].Fischer, C., \& Schornberg, S. (2007). The Competitiveness Situation of the EU Meat Processing and Bevaerage Manufacturing Sectors. Food Economics - Acta Agriculturae Scandinavica Section C, 4(3), 148-158.

[13].Hung, S.C., Hung, S.W., \& Lin, M.J. (2015). Are Alliances a Panacea for SMEs? The Achievement of Competitive Priorities and Firm Performance. Total Quality Management \& Business Excellence, 26(1/2), 190-202.

[14].Joshi, D., Rathore, A. P., Sharma, D., \& Nepal, B. (2011). Determinants of Competitiveness and their Relative Importance. International Journal of services \& Operations Management, 10(4), 426-448.

[15].Kennedy, P., Harrison, R., \& Piedra, M. (1998). Analyzing Agribusiness Competitiveness : The Case of the United States Sugar Industry. International Food and Agribusiness Management Review, 1(2), 245-257.

[16].Kim, J., \& Arnold, P. (1992). Manufacturing Competence and Business Performance: A Framework and Empirical Analysis. International Journal Operation Production, 13(10), 4-26.

[17].Kumar, A., Jaideep, M., Ceasar, D., \& Narayan, D. (1999). A Quality Competitiveness Index for Benchmarking. Benchmarking : An International Journal, 6(1), 12-21.

[18].Lau, R. (2002). Competitve Factors and their Relative Importance in the US Electronics and Computer Industries. International Journal of Operatiosn and Production Management, 22(1), 125-135.

[19]. Meredith, J. (1987). The Strategic Advantages of New Manufacturing Technologies for Small Firms. Strategic Management Journal, 8(3), 249-258.

[20].Molloy, S., \& Schwenk, C. (1995). The Effects of Information Technology on Strategic Decision Making.Journal of Management, 32(3), 283-311.

[21].Porter, M. E. (1980). Competitive Advanatge. New York: Free Press.

[22].Porter, M. E. (1990). The Competitive Advantage Of Nations . London: MacMillan.

[23].Prahalad, C. K., \& Hamel, G. (1990). The Core Competence of the Corporation . Harvard Business Review, 74(4), 7990.

[24].Reddy, S. (2006). Strategic Flexibility and Information Technology Properties: Competitive Advantage and Asset Specificity. Advances in Competitiveness Research, 14(1), 16-43.

[25].Sanchez, R., Heene, A., \& Thomas, H. (1996). Dynamics of Competence-Based Competition. New York: Elsevier Science.

[26].Sanchez-Gutierrez, J., Gonzalez-Uribe, E. G., Gutierrez-Govea, A., \& Garcia-Jimenez, E. F. (2012). The Effects of Intellectual Capital and Innovation on Competitiveness: An Analysis of the Restaurant Industry in Guadalajara, Mexico. Advances in Competitiveness Research, 20(3\&4), 32-46.

[27].Shahnawaz, Adil, M. (2015). Strategic Human Resource Management Practices and Competitive Priorities of the Manufacturing Performance in Karachi. Global Journal of Flexible Systems Management., 16(1), 37-61.

[28].Sharma, B., \& Fisher, T. (1997). Functional Strategies and Competitiveness: An Empirical Analysis using Data from Australian Manufacturing. Benchmarking for Quality Management and Technology, 4(4), 286-294.

[29].Singh, R. K., Garg, S. K., \& Deshmukh, S. (2007). Comparative Study on Strategies of Indian Smal, Medium and Large Scale Organisations. South Asian Journal of Management, 14(3), 44-65.

[30].Teece, D., Pisano, G., \& Shuen, A. (1997). Dynamics Capabilities and Strategic Management. Strategic Management Journal, 18(7), 509-533.

[31].Ward, P., McCreery, T., Ritzman, L., \& Sharma , D. (1998). Competitive Priorities in Operations Management. Decision Sciences, 29(4), 1035-1046. 